\title{
Facile Hydrothermal Synthesis of Hierarchical ZnO with Lignosulphonate and Its Photo Luminescence Property
}

\author{
Yali Xiao, Mingjie Ding, Chongrui Guo, Xiaoguang Lian, Qi Wang', Yuanru Guo*
}

a Key Laboratory of Bio-based Material Science \& Technology (Ministry of Education), College of Material Science and Engineering, Northeast Forestry University, Harbin 150040, China

\author{
xiaoyledu@163.com; ${ }^{\text {a,2}}$ dingmingjie72@163.com \\ "guoyrnefu@163.com; b* panqjitc@163.com
}

Keywords: ZnO nanocrystal, hydrothermal method, sodium lignosulphonate, Hierarchical nsnostructure

\begin{abstract}
ZnO}$ nanomaterials were synthesized by assistant of sodium lignosulphonate (SLS) using hydrothermal method. And nanoplates, nanoflowers structures of $\mathrm{ZnO}$ have been fabricated successfully. XRD、SEM and PL were applied to characterize the prepared ZnO. XRD analysis indicated that prepared $\mathrm{ZnO}$ had preferential growth along the c-axis. The effection of synthesis conditions on ZnO crystal growth were studied by SEM. And the result showed that the concentration of $\mathrm{Zn}^{2+}$ and SLS play an important role on the formation of morphology of $\mathrm{ZnO}$. The results of photolumiscience studies show that hierarchical nanoflowers-like ZnO prepared with SLS has a weaker visible emission. This indicated that the presents of SLS can deduced the defects concentration during $\mathrm{ZnO}$ crystal growth.
\end{abstract}

\section{Introduction}

$\mathrm{ZnO}$ is an important wide band $\operatorname{gap}(\Delta \mathrm{E}=3.37 \mathrm{eV})$ semiconductor material, which has been widely used in ceramics, sensors, solar cells , chemical sensors, photocatalysis and optoelectronic devices(Mishra et al. 2015, Nam and Boo 2016). Up to now, nanostructures of ZnO including prismatic, needle-like, ellipsoidal, tetra-pod-like, nanorod, nanofiber, nanobeltsand nanotubes have been prepared by various physical and chemical methods (Kim et al. 2016, Park et al. 2012).

As one of the most abundant natural polymers on the earth, Lignin has attracted a lot of attention (Glasser et al. 2000). As an important bio-resource, lignin is always obtained as a byproduct in bio-refinery operations and a second generation bio-ethanol from lignocelluloses(Jiang et al. 2010). Lignin is regard as cheap and renewable resource and more and more research try to find its practical application. It has been widely used as technical surfactants with dispersing, stabilizing, and adhesive abilities(Bertoniere et al. 1992, Glasser and Sarkanen 1989, Mao and Wu 2013). Sodium lignosulphonate is an amorphous aromatic biopolymer, which massively arises as a byproduct of pulping industry. The use of lignin as a precursor in the fabrication of new materials has been widely studied (Pu et al. 2011),(Liu et al. 2007).

In this paper, SLS was used to prepare $\mathrm{ZnO}$ nanomaterials. Compared our previous study of preparation ZnO from SLS(Miao et al. 2013), here in this work the hydrothermal method was applied other than precipitation method. And nanoplates, nanoflowers, no-nanoflowers structure has been fabricated successfully.

\section{Materials}

The Sodium lignosulphonate (industrial purity) ( $\mathrm{pH}=4.5-6.0$, water content $\leq 8.5 \%$, insoluble matter $\leq 1.0 \%$, sugar content $\leq 12.0 \%, \mathrm{Ca}$ and $\mathrm{Mg}$ content $\leq 1.5 \%$, and inorganic salt $\left(\mathrm{Na}_{2} \mathrm{SO}_{4}\right)$ $\leq 5.0 \%$ ) was supplied by Qianjin Fuli Limited Company in the Jilin province of China. Zinc acetate $\left[\mathrm{Zn}\left(\mathrm{CH}_{3} \mathrm{COO}\right)_{2} \cdot 2 \mathrm{H}_{2} \mathrm{O}\right]$ (Baker, crystals, 99\% purity) and sodium hydroxide ( $\mathrm{NaOH}$, flakes, 97\% purity) were used as the Zinc source and precipitant, respectively. All the chemicals were used as 
received without any further purification.

\subsection{Experiment}

In a typical process, SLS was put into $30 \mathrm{~mL} \mathrm{Zn}^{2+}$ solution under ultrasonic oscillating. Then the sulution was added by $30 \mathrm{~mL} 2 \mathrm{~mol} \cdot \mathrm{L} \mathrm{NaOH}$ and $20 \mathrm{~mL}$ ethanol. The mixture was transferred to the teflon-lined stainless autoclave and maintained at $130^{\circ} \mathrm{C}$ for $14 \mathrm{~h}$. After cooled to room temperature, the obtained products were washed with deionized water for several times and then the as-fabricated products were collected. The obtained $\mathrm{ZnO}$ then was calcined at $550^{\circ} \mathrm{C}$ for $2 \mathrm{~h}$ (heating rate: $5^{\circ} \mathrm{C} \cdot \mathrm{min}^{-1}$ ) in the air.

\subsection{Results and analysis}

\subsubsection{XRD}

Figure 1 presents XRD results of as-synthesized samples with and without Sodium lignosulphonate. All the diffraction peaks are attributed to the hexagonal wurtzite phase of $\mathrm{ZnO}$ (JCPDS card NO. 36-1451). No characteristic peaks of impurity, such as $\mathrm{Zn}$, ZnOH and $\mathrm{ZnCO}_{3}$ were observed. As we see from the XRD pattens, the peak width of ZnO prepared by SLS increased compare to $\mathrm{ZnO}$ prepared without SLS. According to the Scherrer formula L(hkl) = $0.9 \lambda / \Delta(\mathrm{hkl}) \cos \theta$, the crystallite sizes of $\mathrm{ZnO}$ prepared without and with SLS were 61.8 and 30nm, respectively. This indicated that the present of SLS limited the growth of ZnO crystals and lead to the decrease of $\mathrm{ZnO}$ crystallite size. Compare to the $\mathrm{ZnO}$ prepared without SLS, the ZnO prepared with SLS show stronger intensity of (002), it implies $\mathrm{ZnO}$ has preferential growth along the c-axis when SLS was used.

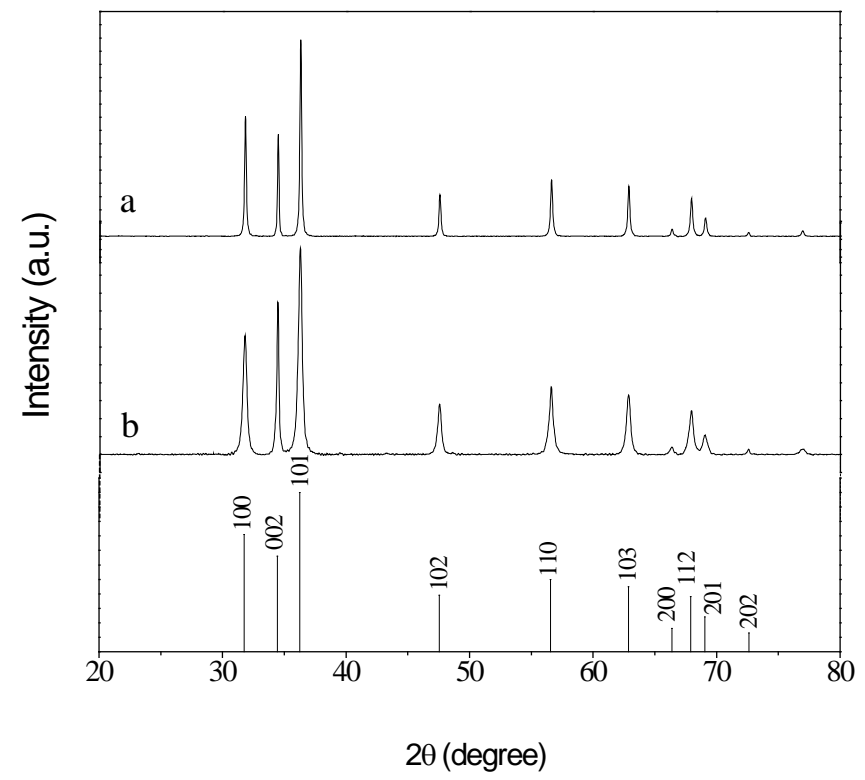

Figure 1 XRD spectra of as-synthesized ZnO crystals samples (a) without and (b) with $2 \mathrm{~g}$ SLS and the standard hexagonal wurtzite phase of $\mathrm{ZnO}$.

\subsubsection{SEM}

Figure 2 presents the SEM images of prepared $\mathrm{ZnO}$. From figure 2(a), we can see that $\mathrm{ZnO}$ prepared without SLS was shown as irregular plates. The width and length of plates was $0.5 \mu \mathrm{m}$ and $0.7 \mu \mathrm{m}$, respectively. When SLS was used during preparations, the prepared $\mathrm{ZnO}$ with certain morphology appeared, as shown in figure 2(b, c and d). We can see in figure 2(b) that ZnO featured as flowers were prepared when $1 \mathrm{~g}$ SLS was used. And these $\mathrm{ZnO}$ flowers are made by nanoplates with the thickness of $0.09 \mu \mathrm{m}$. Increase the addictive amount of SLS to $2 \mathrm{~g}$, fine hierarchical $\mathrm{ZnO}$ flowers are obtained with the thickness of $0.02 \mu \mathrm{m}$ to sub-unit of petal plates. The diameter of these nanoflowers were about $1 \sim 2 \mu \mathrm{m}$. These hierarchical nanoflowers show better 3D structure by forming nanoplates interfacing with each other, which may result in larger specific surface area and better properties. However, when improved the amount of SLS (3g), nanorods were found in 
figure 2(d). All the results give the evidence that SLS play an important role on formation the certain morphology of $\mathrm{ZnO}$. By controlling the amounts of SLS, we can get the certain $\mathrm{ZnO}$ morphology.
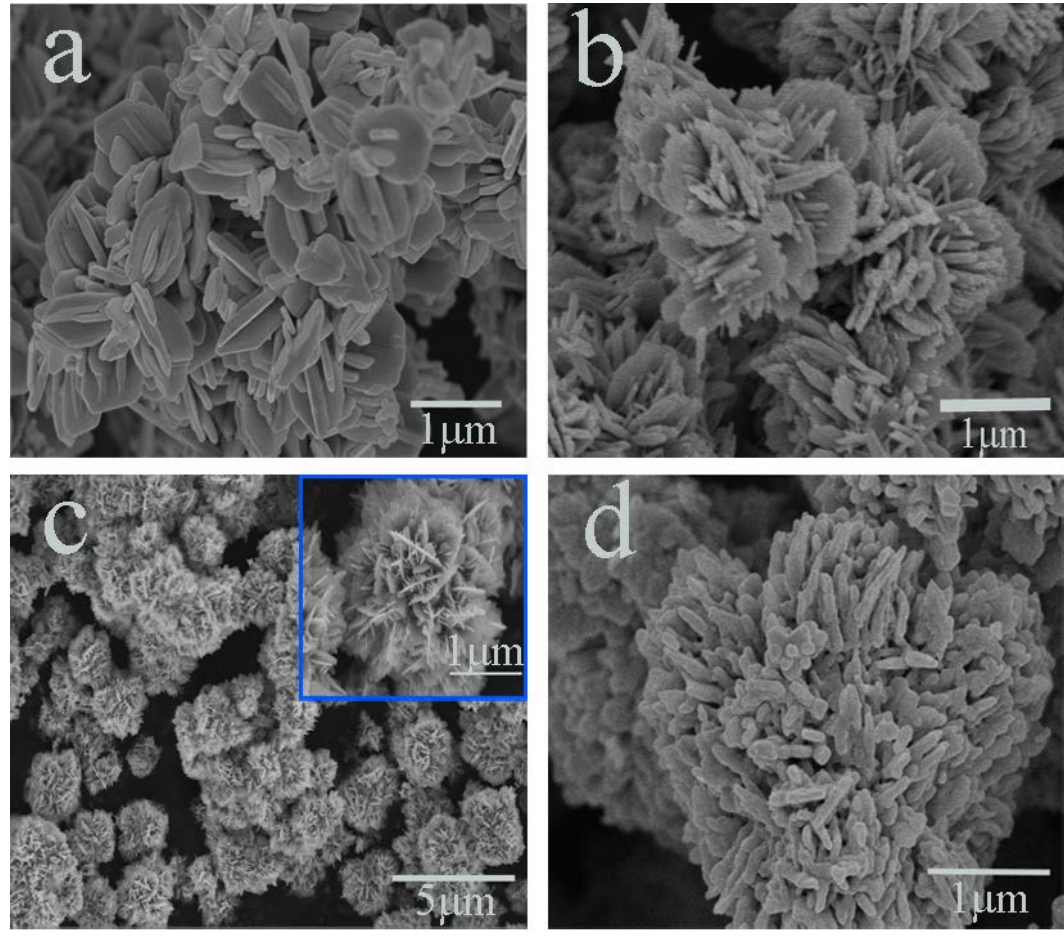

Figure 2 SEM of ZnO which the weight of SLS was (a)0g; (b)1g; (c)2g and (d)3g prepared by the $0.4 \mathrm{~mol} \cdot \mathrm{L}$ of $\mathrm{Zn}^{2+}$.

In order to study the effects of concentration of $\mathrm{Zn}^{2+}$ on preparation of $\mathrm{ZnO}$, The experiments using different concentration of $\mathrm{Zn}^{2+}$ were carried out and their morphology are shown in figure 3 . $\mathrm{ZnO}$ nanocrystals fabricated by $0.2 \mathrm{~mol} \cdot \mathrm{L} \mathrm{Zn}^{2+}$ presents morphology of well dispersed nanoplates, as we can see in figure 3(a). Improving the concentration of $\mathrm{Zn}^{2+}$ in precursor solution, $\mathrm{ZnO}$ with morphology of hierarchical nanoflowers appeared. We can see these nanoflowers clearly in figure 3(b-c). The diameter of these nanoflowers were about $1 \sim 2 \mu \mathrm{m}$. To the $\mathrm{ZnO}$ prepared by $0.4 \mathrm{~mol} \cdot \mathrm{L}$ $\mathrm{Zn}^{2+}$, hierarchical nanoflowers show better 3D structure by more nanoplates interfacing with each other, which may result in larger specific surface area and better properties. Further increase the concentration of $\mathrm{Zn}^{2+}$, hierarchical nanoflowers seem to collapse, as seen in figure $3 \mathrm{~d}$. 

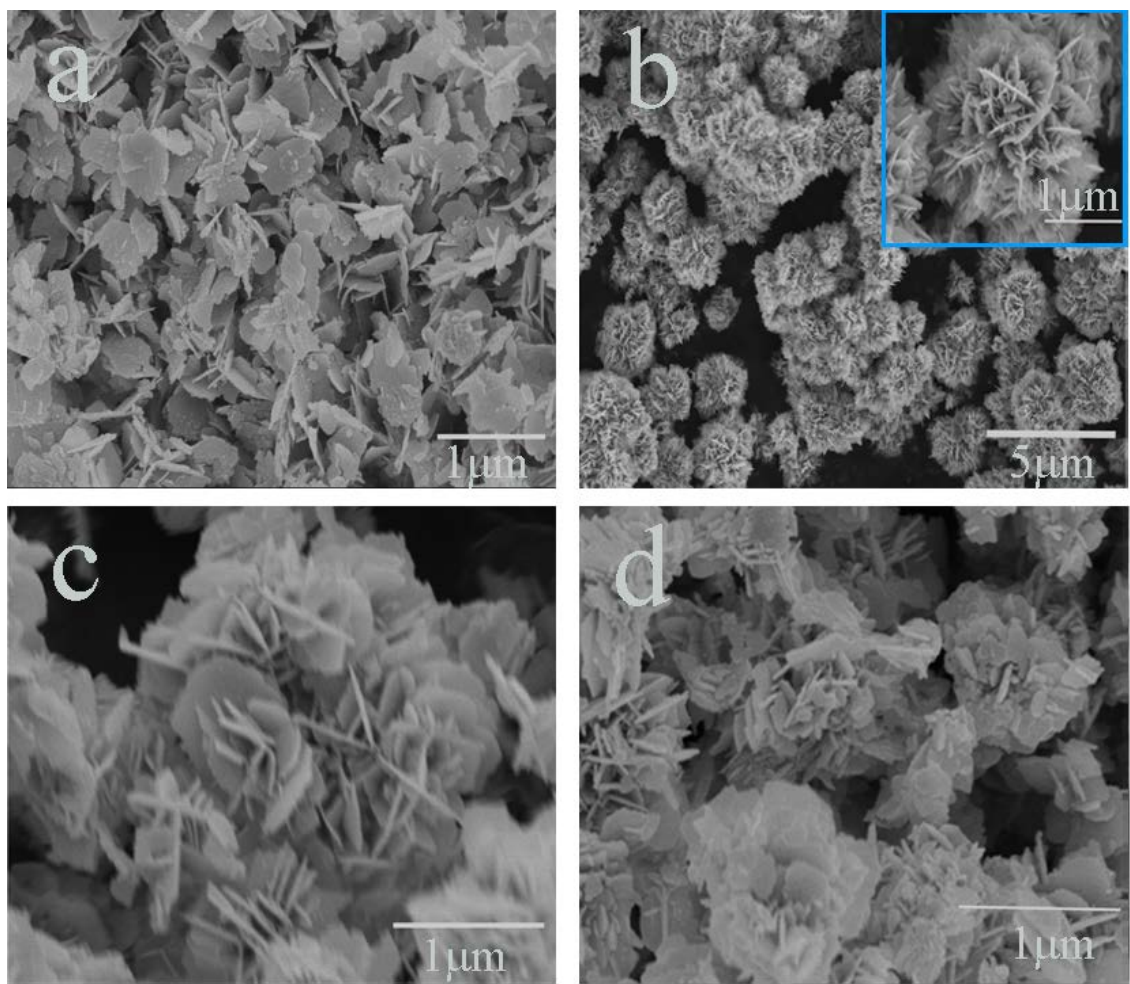

Figure 3 SEM images of ZnO prepared with 2 g SLS and (a) 0.2; (b) 0.4; (c) 0.6 and (d) 0.8(mol·L) $\mathrm{Zn}^{2+}$.

\subsubsection{BET}

Specific surface areas of the $\mathrm{ZnO}$ were determined by BET method as shown in figure 4 . One can see that the BET specific surface areas of $\mathrm{ZnO}$ are strongly affected by the added amount of SLS used in the preparation. If SLS is not added, then obtained ZnO has specific surface area as low as $14.6 \mathrm{~m}^{2} \cdot \mathrm{g}^{-1}$. In contrast, upon adding SLS, the specific surface area of $\mathrm{ZnO}$ will increase to more than $25 \mathrm{~m}^{2} \cdot \mathrm{g}^{-1}$. On the condition of $2 \mathrm{~g}$ SLS, the hierarchical ZnO flowers has the largest specific surface area of $42.6 \mathrm{~m}^{2} \cdot \mathrm{g}^{-1}$.

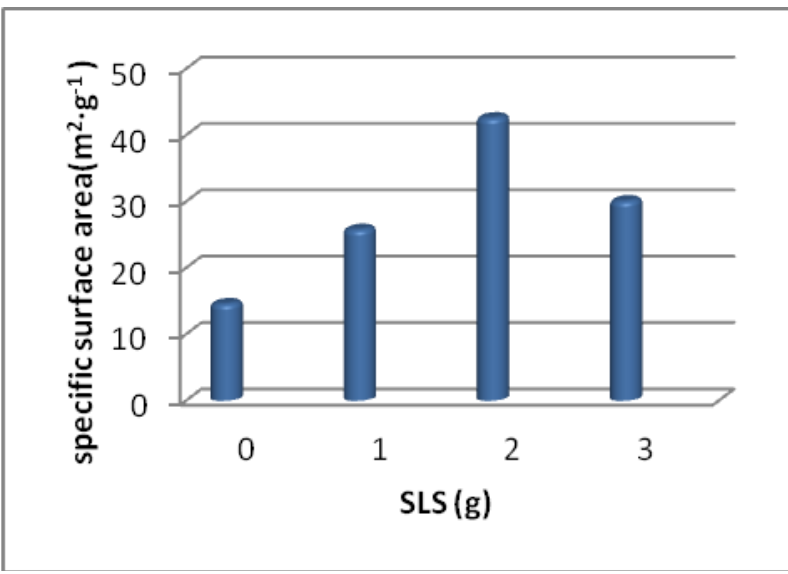

Figure 4 specific surface area of ZnO prepared with amount of SLS

\subsubsection{The Photoluminescence Properties}

The photoluminescence (PL) properties of our $\mathrm{ZnO}$ were studied in figure 5. From the figure 5, we can see that all $\mathrm{ZnO}$ has two emission peaks. To the $\mathrm{ZnO}$ prepared without SLS, it shows an UV band emission at $385 \mathrm{~nm}$ and a strong and broad emission covered almost visible band from 400-650 $\mathrm{nm}$. While to the $\mathrm{ZnO}$ prepared with $2 \mathrm{~g}$ SLS, we can see a less strong emission of UV band centered at $385 \mathrm{~nm}$ with a weak and broad visible band emission. It is reported that visible band emission of $\mathrm{ZnO}$ is caused by defects of $\mathrm{ZnO}$, such as Oxygen vacancies and $\mathrm{Zn}$ interstitials, which were formed during the formation of $\mathrm{ZnO}$ crystals. The visible emission became weak after adding 
the SLS indicated that SLS has deduced defects concentration of $\mathrm{ZnO}$.

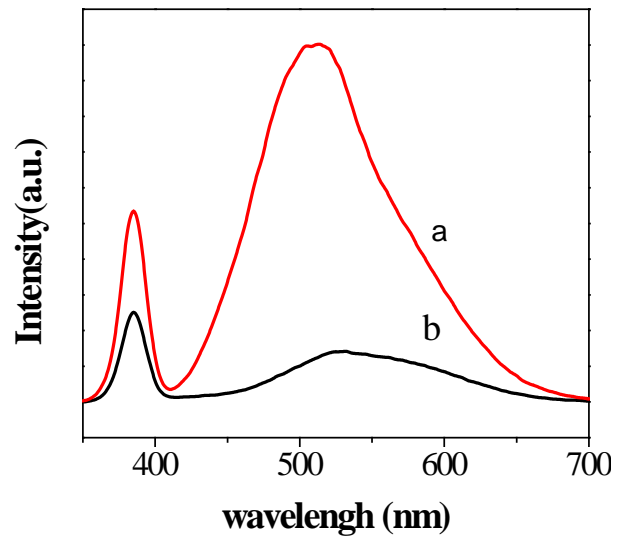

Figure 5 Room-temperature photoluminescence emission spectra of $\mathrm{ZnO}$ prepared a )without SLS, b) with 2 g SLS

\section{Conclusion}

$\mathrm{ZnO}$ nanocrystals were synthesized by hydrothermal method with SLS. Changing the concentration of $\mathrm{Zn}^{2+}$ in precursor solution, we fabricated $\mathrm{ZnO}$ with morphology of nanoplates and nanoflowers with SLS. The amount of SLS also plays an important role on the formation of ZnO. The SLS can limit the growth of ZnO crystals and decreased the crystallite size. By using $2 \mathrm{~g}$ SLS, hierarchical nanoflowers-like $\mathrm{ZnO}$ with high specific surface area was obtained. Meanwhile, PL spectra showed that the present of SLS during the preparation can deduce the defect concentration of $\mathrm{ZnO}$.

\section{Acknowledgements}

This work was supported by the National Undergraduates Training Programs of Innovation (Northeast Forestry University) ( 201710225055).

\section{References}

[1] Bertoniere N, King W, Hughs S. 1992. Lignocellulosics-Science, Technology, Development and Use: Ellis Horwood Ltd., Chichester, England.

[2] Glasser WG, Sarkanen S. 1989. Lignin: properties and materials. ACS Symposium series: American Chemical Society.

[3] Glasser WG, Northey RA, Schultz TP. 2000. Lignin: historical, biological, and materials perspectives: American Chemical Society Washington, DC.

[4] Jiang G, Nowakowski DJ, Bridgwater AV. 2010. A systematic study of the kinetics of lignin pyrolysis. Thermochimica Acta 498: 61-66.

[5] Kim YJ, Lee HS, Noh J-S. 2016. Transient behaviors of ZnO thin films on a transparent, flexible polyethylene terephthalate substrate. Thin Solid Films 603: 160-164.

[6] Liu Y, Gao L, Sun J. 2007. Noncovalent functionalization of carbon nanotubes with sodium lignosulfonate and subsequent quantum dot decoration. Journal Of Physical Chemistry C 111: 1223-1229.

[7] Mao CP, Wu SB. 2013. Synergistic Effects of Lignin-Phenol-based Nonionic Surfactant with Anionic Surfactants in Aqueous Solution. Bioresources 8: 5025-5035.

[8] Miao TT, Guo YR, Pan QJ. 2013. The SL-assisted synthesis of hierarchical ZnO nanostructures and their enhanced photocatalytic activity. Journal of Nanoparticle Research 15. 
[9] Mishra YK, et al. 2015. Direct Growth of Freestanding ZnO Tetrapod Networks for Multifunctional Applications in Photocatalysis, UV Photodetection, and Gas Sensing. ACS Applied Materials \& Interfaces 7: 14303-14316.

[10]Nam S-H, Boo J-H. 2016. Enhancement of photocatalytic activity of synthesized ZnO nanoparticles with oxygen plasma treatment. Catalysis Today 265: 84-89.

[11]Park S, An S, Ko H, Jin C, Lee C. 2012. Synthesis of Nanograined ZnO Nanowires and Their Enhanced Gas Sensing Properties. ACS Applied Materials \& Interfaces 4: 3650-3656.

[12] Pu Y, Kosa M, Kalluri UC, Tuskan GA, Ragauskas AJ. 2011. Challenges of the utilization of wood polymers: how can they be overcome? Applied Microbiology and Biotechnology 91: 1525-1536. 